\title{
Moving from controversy to consensus: premedication for neonatal intubation
}

\author{
Lindsay Johnston $\mathbb{D}^{1} \cdot$ Soo Hyun Kwon ${ }^{1}$
}

Received: 16 February 2018 / Accepted: 12 March 2018 / Published online: 22 June 2018

(c) Nature America, Inc., part of Springer Nature 2018

Neonatal tracheal intubation is a high-risk procedure for patients in neonatal intensive care units (NICUs), and can be associated with multiple adverse events, both short term and long term. Premedication for this procedure, including sedation and paralytics, has been shown to improve success rates and potentially mitigate the risk of airway injury. However, despite the awareness of these benefits, there has been significant variability in the adoption of this practice. Neonatal tracheal intubation is a common but potentially high-risk procedure for patients in NICUs [1]. Unsuccessful attempts are frequent [2], as are adverse events such as significant oxygen desaturation [3], bradycardia [4], and potential airway injury [5]. These risks are even more significant for preterm infants, with recent authors reporting increased risk of severe intraventricular hemorrhage (IVH) and adverse neurodevelopmental outcomes in patients requiring multiple intubation attempts $[4,6,7]$. Taken together, these concerns present a major challenge for neonatal care providers, and significant effort is being dedicated towards improving the safety of this critical procedure.

The use of sedation and paralytic agents to facilitate nonemergent neonatal tracheal intubation and potentially mitigate the risk of adverse outcomes has been a topic of much discussion for many years. Premedication for intubation is utilized commonly in adult and pediatric populations [8]. Numerous authors have reported improvement in procedural success rates and decreased risk of airway injury in the neonatal population when premedication is utilized for tracheal intubation [9-16]. However, despite the identified benefits of premedication and issuance of an endorsement supporting its use by the American Academy of

Lindsay Johnston

Lindsay.johnston@yale.edu

1 Department of Pediatrics, Yale University School of Medicine, 333 Cedar Street, New Haven, CT 06520, USA
Pediatrics in 2010 [17], there has been significant variability in the adoption of the use of sedation and paralytic agents for tracheal intubation premedication across NICUs nationally, and many individual providers have not incorporated routine use of premedication into their practice $[18,19]$.

Institutional and individual provider variation in the routine use of premedication for intubation likely has many contributing factors. Some of the common concerns raised by providers are listed here, along with potential strategies to alleviate concern or decrease potential risk:

(1) Personal preference: Providers initially trained to intubate patients without using premedication may feel that, since they are generally able to secure the airway, these additional steps are not necessary and only serve to delay or prolong the procedure. However, as evidence continues to mount that use of premedication may result in both shortterm and long-term benefits to patients in terms of improved physiologic stability, lower risk of adverse events/airway injury, and decreased risk of associated IVH and poor neurodevelopmental outcomes, the importance of using premedication for tracheal intubation becomes more clear.

(2) Inability to secure airway in an apneic patient: Intubators may have concern about potentially having difficulty securing the airway in a patient without spontaneous respiratory effort, which would be the case after premedication with sedation and paralytic medications. This can be addressed on several fronts. Proactively identifying risk factors for airway abnormalities, which are often evident in the patient history or physical exam findings, might alter the planning for the procedure (including personnel present, equipment used, and choice of premedication) and could help to mitigate this risk. As noted above, the utilization of premedication often improves procedural success rates, and in the event of adverse medication side effects, reversal agents could be administered.

(3) Lack of familiarity with medication regimen or concern about side effects: Providers who are not experienced in the utilization of sedation/paralytic agents for neonatal 
intubation premedication may be unfamiliar with the medication regimens used, and may have concern about potential side effects. To address this issue, development of institutional guidelines that list preferred medications, dosing information, and order of administration may improve clarity. Simulation sessions could be conducted to improve familiarity with the regimen. As noted above, in the case of adverse events, reversal agents for narcotics and paralytics should be easily accessible and able to be rapidly administered in patients receiving premedication for intubation.

(4) Possible deterioration in patient status: Providers may have concern about transient deterioration in patient status, including desaturation and hypercarbia, and after receiving premedication for intubation, including paralytic agents. Oftentimes, this is related to an underestimation in the amount of ventilator support required while the paralytic agents are inhibiting spontaneous respiration. Teams should be cognizant of the infant's spontaneous respiratory rate when choosing ventilator settings, and should carefully monitor tidal volumes, oxygen saturation, and carbon dioxide levels closely to identify when increased support is required.

(5) Prolonged time required to prepare and administer medications: The process of getting the medications to the patient prior to the procedure, including placing the orders, verification of orders by pediatric pharmacists, drawing up, and administering the medications, may take a significant amount of time, and decrease the feasibility of utilizing premedication. Possible solutions for this issue include the development of dedicated "kits" for intubation premedication that are easily accessible in the NICU, identifying potential patients who may require premedication in advance, and working with hospital pharmacists and nurses in quality improvement efforts to streamline the process.

The concerns raised above certainly need to be addressed, but the data that have been presented to date suggest that utilizing premedication for neonatal tracheal intubation has significant clinical benefit, especially in larger, more mature infants. The article published by Krick et al. in this issue fills an important gap because it provides data about the use of sedation and paralytics in the very low birth weight population. In general, many providers have been reluctant to utilize intubation premedication for these patients due to anticipation of increased procedural difficulty given smaller patient size and concern about medication side effects. It is reassuring that these authors were able to demonstrate that premedication for neonatal intubation, including use of paralytics, improved success rates, decreased adverse events during the procedure, and resulted in less bradycardia and physiologic instability. As these authors note, there are numerous areas in which more research will be needed to determine the effectiveness and safety of using premedication for tracheal intubation, especially in very low birth weight and extremely low birth weight infants. In addition to the obvious benefit of preventing procedure-related discomfort [20], these neonates will likely have significant potential benefit from premedication for intubation, most notably, through paralyticmediated attenuation of increased intracranial pressures during attempts [21], which are related to risk of severe IVH [22], and potential for increased success rates, which could translate to improved neurodevelopmental outcomes [7]. However, additional clinical studies will be necessary to confirm these benefits and assess for potential areas of risk.

In addition to the utilization of premedication for intubation, there are many additional areas being investigated to improve the safety of neonatal intubation. These include use of videolaryngoscopy [23, 24], development of robust educational methods for intubation education and training (e.g., utilizing skills checklists with robust evidence of validity and requiring assessment of competency on a simulator prior to performing clinical attempts on a patient) [25], and application of quality improvement methodologies. This area of study remains a very high priority for those individuals who care for the tiny and most fragile members of our population, and through continued collaborative efforts and research, we will surely be able to establish best practices and improve the outcomes of our patients.

\section{Compliance with ethical standards}

Conflict of interest The authors declare that they have no conflict of interest.

\section{References}

1. Sawyer T, Foglia E, Hatch LD, Moussa A, Ades A, Johnston L, et al. Improving neonatal intubation safety: a journey of a thousand miles. J Neonatal Perinat Med. 2017;10:125-131.

2. Haubner LY, Barry JS, Johnston LC, Soghier L, Tatum PM, Kessler D, et al. Neonatal intubation performance: room for improvement in tertiary neonatal intensive care units. Resuscitation. 2013;84:1359-1364.

3. Foglia EE, Ades A, Napolitano N, Leffelman J, Nadkarni V, Nishisaki A. Factors associated with adverse events during tracheal intubation in the NICU. Neonatology. 2015;108:23-29.

4. Hatch LD, Grubb PH, Lea AS, Walsh WF, Markham MH, Maynord PO, et al. Interventions to improve patient safety during intubation in the neonatal intensive care unit. Pediatrics. 2016;138:e1-e9.

5. Holzki J, Laschat M, Puder C. Iatrogenic damage to the pediatric airway. Mechanisms and scar development. Paediatr Anaesth. 2009;19 Suppl 1:131-146.

6. Sauer CW, Kong JY, Vaucher YE, Finer N, Proudfoot JA, Boutin MA, et al. Intubation attempts increase the risk for severe intraventricular hemorrhage in preterm infants-a Retrospective Cohort Study. J Pediatr. 2016;177:108-113.

7. Wallenstein MB, Birnie KL, Arain YH, Yang W, Yamada NK, Huffman LC, et al. Failed endotracheal intubation and adverse 
outcomes among extremely low birth weight infants. J Perinatol. 2016;36:112-115.

8. Gerardi MJ, Sacchetti AD, Cantor RM, Santamaria JP, Gausche $\mathrm{M}$, Lucid W, et al. Rapid-sequence intubation of the pediatric patient. Pediatric Emergency Medicine Committee of the American College of Emergency Physicians. Ann Emerg Med. 1996;28:55-74.

9. Roberts KD, Leone TA, Edwards WH, Rich WD, Finer NN. Premedication for nonemergent neonatal intubations: a randomized, controlled trial comparing atropine and fentanyl to atropine, fentanyl, and mivacurium. Pediatrics. 2006;118: $1583-1591$.

10. Lemyre B, Cheng R, Gaboury I. Atropine, fentanyl and succinylcholine for non-urgent intubations in newborns. Arch Dis Child Fetal Neonatal Ed. 2009;94:F439-442.

11. Dempsey EM, Al Hazzani F, Faucher D, Barrington KJ. Facilitation of neonatal endotracheal intubation with mivacurium and fentanyl in the neonatal intensive care unit. Arch Dis Child Fetal Neonatal Ed. 2006;91:F279-282.

12. Pereira e Silva Y, Gomez RS, Marcatto Jde O, Maximo TA, Barbosa RF, Simoes e Silva AC. Morphine versus remifentanil for intubating preterm neonates. Arch Dis Child Fetal Neonatal Ed. 2007;92:F293-294.

13. Ghanta S, Abdel-Latif ME, Lui K, Ravindranathan H, Awad J, Oei J. Propofol compared with the morphine, atropine, and suxamethonium regimen as induction agents for neonatal endotracheal intubation: a randomized, controlled trial. Pediatrics. 2007;119:e1248-1255.

14. Carbajal R, Eble B, Anand KJ. Premedication for tracheal intubation in neonates: confusion or controversy? Semin Perinatol. 2007;31:309-317.

15. Le CN, Garey DM, Leone TA, Goodmar JK, Rich W, Finer NN. Impact of premedication on neonatal intubations by pediatric and neonatal trainees. J Perinatol. 2014;34:458-460.
16. Feltman DM, Weiss MG, Nicoski P, Sinacore J. Rocuronium for nonemergent intubation of term and preterm infants. J Perinatol. 2011;31:38-43.

17. Kumar P, Denson SE, Mancuso TJ, Committee on F, Newborn SoA, Pain M. Premedication for nonemergency endotracheal intubation in the neonate. Pediatrics. 2010;125:608-615.

18. Muniraman HK, Yaari J, Hand I. Premedication use before nonemergent intubation in the newborn infant. Am J Perinatol. 2015;32:821-824.

19. Sarkar S, Schumacher RE, Baumgart S, Donn SM. Are newborns receiving premedication before elective intubation? J Perinatol. 2006;26:286-289.

20. Caldwell CD, Watterberg KL. Effect of premedication regimen on infant pain and stress response to endotracheal intubation. $\mathrm{J}$ Perinatol. 2015;35:415-418.

21. Friesen RH, Honda AT, Thieme RE. Changes in anterior fontanel pressure in preterm neonates during tracheal intubation. Anesth Analg. 1987;66:874-878.

22. Raju TN, Vidyasagar D, Torres C, Grundy D, Bennett EJ. Intracranial pressure during intubation and anesthesia in infants. $\mathrm{J}$ Pediatr. 1980;96:860-862.

23. Johnston LC, Chen R, Whitfill TM, Bruno CJ, Levit OL, Auerbach MA. Do you see what I see? A randomised pilot study to evaluate the effectiveness and efficiency of simulation-based training with videolaryngoscopy for neonatal intubation. BMJ Stel. 2015;1:12-18.

24. Moussa A, Luangxay Y, Tremblay S, Lavoie J, Aube G, Savoie E, et al. Videolaryngoscope for teaching neonatal endotracheal intubation: a randomized controlled trial. Pediatrics. 2016;137:1-8.

25. Sawyer T, White M, Zaveri P, Chang T, Ades A, French H, et al. Learn, see, practice, prove, do, maintain: an evidence-based pedagogical framework for procedural skill training in medicine. Acad Med. 2015;90:1025-1033. 